\title{
Spatial and temporal variability of sea breezes and synoptic influences over the surface wind field of the Yucatán Peninsula
}

\author{
Miguel A. CAHUICH-LÓPEZ ${ }^{1 *}$, Ismael MARIÑO-TAPIA ${ }^{1,2}$, Alejandro José SOUZA ${ }^{1}$, \\ Gerardo GOLD-BOUCHOT ${ }^{3}$, Mark COHEN $^{4}$ and David VALDÉS LOZANO 5
}

${ }^{1}$ Laboratorio de Procesos Costeros y Oceanografia Física, Centro de Investigación y de Estudios Avanzados del Instituto Politécnico Nacional, Unidad Mérida, km. 6 Antigua Carretera a Progreso, A.P. 73 Cordemex, 97310 Mérida, Yucatán, México.

${ }^{2}$ Escuela Nacional de Estudios Superiores (ENES)-Mérida, UNAM Calle 7B 229, Col. Juan B. Sosa, 97205 Mérida, Yucatán, México.

${ }^{3}$ Oceanography Department and Geochemical and Environmental Research Group, College of Geosciences, Texas A\&M University, 3148 TAMU, College Station, Texas 77843-3148, USA.

${ }^{4}$ National Oceanic and Atmospheric Administration, Air Resources Laboratory, NCWCP, R/ARL, Rm. 4265, 5830 University Research Court, College Park, Maryland 20740, USA.

${ }^{5}$ Laboratorio de Química Marina, Centro de Investigación y de Estudios Avanzados del Instituto Politécnico Nacional, Unidad Mérida, km. 6 Antigua Carretera a Progreso, A.P. 73 Cordemex, 97310 Mérida, Yucatán, México.

*Corresponding author; email: miguel.cahuich@cinvestav.mx

Received: May 14, 2019; accepted: October 17, 2019

\begin{abstract}
RESUMEN
El equilibrio entre los fenómenos atmosféricos sinópticos y la brisa marina puede influir profundamente en la circulación en las regiones costeras. En este artículo se describen los patrones cuasi permanentes de dicha variabilidad en el campo de vientos de superficie de la Península de Yucatán. Para lograr esto se realizó un análisis de funciones empíricas ortogonales complejas (CEOF) sobre 10 años (mayo 2007-mayo 2017) de modelaciones de vientos en superficie del modelo North American Mesoscale Forecast System (NAM). Se aplicó un filtro paso alto/paso bajo a las series de tiempo obtenidas del CEOF, para estudiar el comportamiento temporal de alta y baja frecuencia de los modos. Los resultados muestran que, de octubre a marzo, los frentes fríos dominan en dos patrones diferentes (dos primeros modos), lo cual amortigua los vientos locales que muestran una mayor amplitud durante la noche (brisas de tierra) que durante el día (brisas marinas). La influencia de los sistemas tropicales al final de esta temporada, aunque menor, es notable (tercer modo). De abril a septiembre, la península está dominada por brisas marinas acentuadas sobre la plataforma occidental (primer modo), mientras que las brisas terrestres exhiben una menor dominancia que las brisas marinas (tercer modo). En este periodo, los frentes fríos y los sistemas tropicales (modo 2) ejercen una influencia más suave sobre los vientos locales. Un fenómeno distintivo visto en las altas frecuencias del segundo modo durante este periodo es la ocurrencia de brisas marinas en toda la península. Los resultados de este trabajo tienen implicaciones importantes para la dispersión de contaminantes atmosféricos, la generación de oleaje por el viento y la erosión costera, entre otros.
\end{abstract}

\section{ABSTRACT}

The balance between synoptic and sea breeze atmospheric phenomena can profoundly influence atmospheric circulation in coastal regions. In this paper, a comprehensive study to understand the quasi-permanent patterns of such variability over the surface wind field of the Yucatán Peninsula is described. We performed a Complex Empirical Orthogonal Function (CEOF) analysis on 10 years (May 2007-May 2017) of modeled surface winds from the North American Mesoscale Forecast System (hereafter, NAM). High-pass/low-pass 
filtering was applied to the time series obtained from the CEOF analysis, to study the high and low-frequency temporal behavior that can be associated with the modes. Results show that for the period from October to March, cold fronts dominate in two different patterns (first two modes), which damp the local winds that show higher amplitude during the nighttime (land breezes) than during the daytime (sea breezes). By the end of this season, the influence of tropical systems, although smaller, is noticeable (third mode). From April to September the peninsula is dominated by sea breezes accentuated at the western shelf (first mode) while land breezes exhibit lesser dominance than sea breezes (third mode). In this period cold fronts and tropical systems (mode 2) exert milder influence over local winds. A distinctive phenomenon seen in the high frequencies of the second mode during this period is the occurrence of peninsula-wide sea breeze. The results of this work have important implications for atmospheric pollutant dispersion, wind wave generation and coastal erosion, among others.

Keywords: Complex Empirical Orthogonal Function Analysis, surface wind variability, cold northerlies, Yucatán Peninsula.

\section{Introduction}

Wind variability has a strong influence on several important processes occurring on coastal zones. The duration and frequency of these - from daily varying sea breezes to longer term synoptic influences - affect air pollution dispersion (Bornstein and Thompson, 1981; Lalas et al., 1983; Berlyand, 1991), beach morphodynamics (Masselink, 1998), coastal ocean circulation and mixing (Zavala-Hidalgo et al., 2014), amongst others. For instance, in the Yucatán Peninsula (YP) sea breezes and cold fronts have been identified as major drivers of coastal dynamics (Torres-Freyermuth et al., 2017) and the last ones as upwelling disruptors (Reyes-Mendoza et al., 2016). Sea breezes and land breezes also play an important role in the wind power potential of the YP (Figueroa-Espinoza et al., 2014).

The YP is in eastern Mexico, between the Gulf of Mexico (GoM) and the Caribbean Sea, within the trade winds belt. Thus, the prevailing wind direction is largely influenced by the variability of the North Atlantic Subtropical High (NASH), being northeasterly in winter months and easterly-southeasterly in summer months (Davis et al., 1997). During summer months, there are other important synoptic influences such as tropical waves (Serra et al., 2010) and tropical cyclones (Kimball and Mulekar, 2004). In winter, when NASH is weaker, mid-latitude migratory high-pressure systems move equatorward, allowing cold northerlies (known locally as "nortes") associated with the leading edge of polar air masses (i.e., cold fronts) to reach the YP. Although most of the cold fronts enter the region during the winter months, October, November and March are also considered as frontal activity months (DiMego et al., 1976; Henry, 1979).

Pérez-Santos et al., (2010) estimated the main modes of variability of synoptic scale sea winds over the Yucatán basin-Caribbean Sea; in summer, the first, second and third modes were related to tropical waves, low-pressure systems, and hurricanes, respectively; in winter, extratropical low pressure systems and cold fronts were associated with the first mode. These authors did not analyze the presence and behavior of sea breezes and their influence on wind patterns on the continental landmass of YP, as included in the present work.

Due to its condition as a peninsula, and in response to the daily temperature gradient between a warmer landmass and the sea, cooler marine air may propagate inland form around all the YP shorelines (i.e., sea breeze). The evolution of the sea breezes will depend on several factors, but the strength of the synoptic flow is an important control (Estoque, 1962; Simpson, 1994). Other factors include the Coriolis force, the topography (Miller et al., 2003) and the land width (Xian and Pielke, 1991). During the night, the horizontal temperature (and pressure) gradient is reversed (the land cools faster than sea surface) and a mild "land breeze" can take place, causing a reversal of the wind flow (seaward winds; Lutgens and Tarbuck, 2013).

There are some insights in the literature about the sea/land-breeze spatiotemporal variability in the YP. Gille et al. (2003), who analyzed the differences between morning and evening sea winds, found some regions of the trade wind belt, and particularly the western shelf of the YP, with 


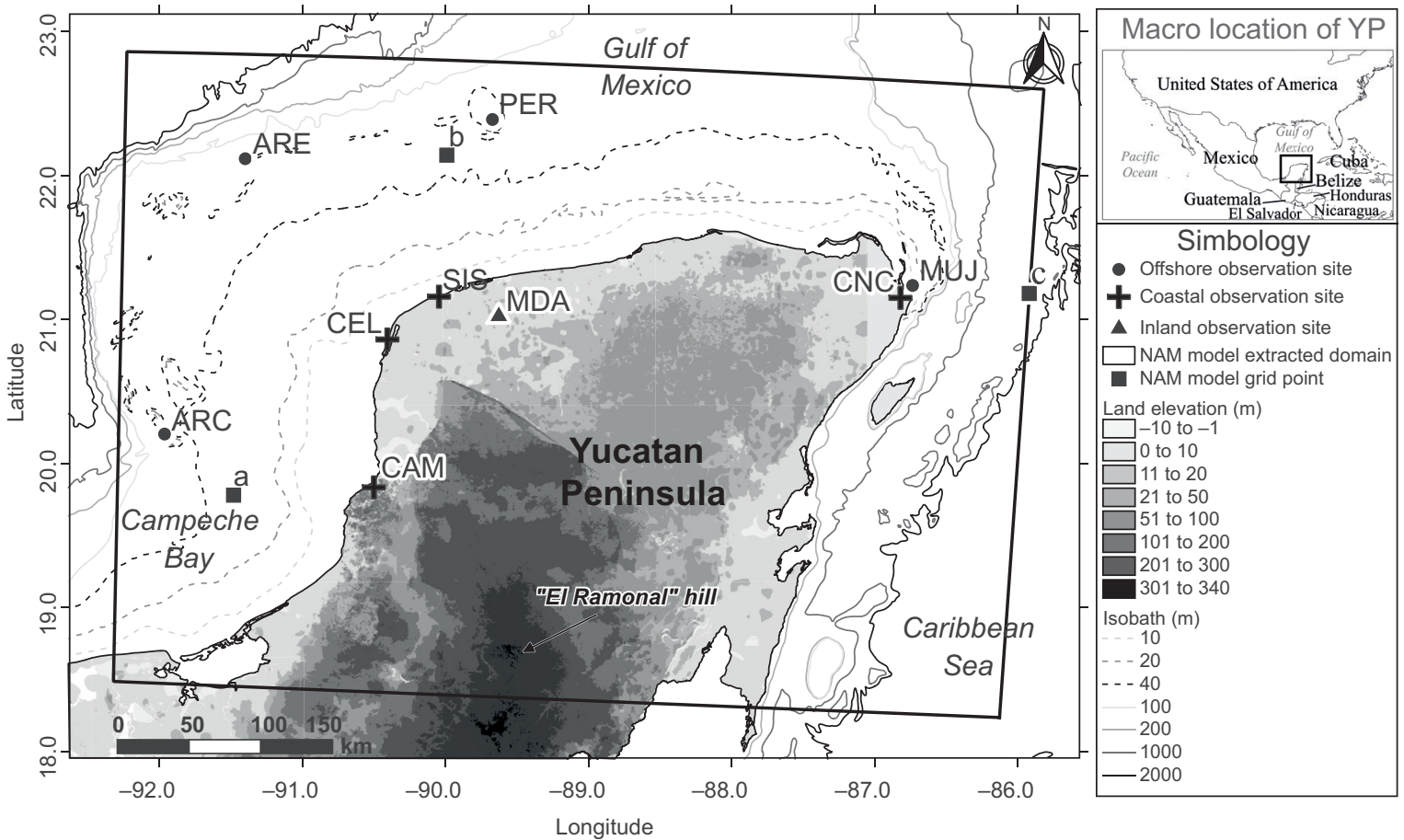

Fig. 1. Study area and location of the numerical domain extracted from the model. Observation sites selected for model comparison (see details in Table I of the supplementary material [Table SM-I]) and three offshore NAM grid points used to estimate both the cross-shore temperature and pressure gradients over the shelf of the YP (see explanation in section 3.2).

significant sea breeze signature. This reinforces the idea that in the GoM the greatest eccentricity of the diurnal wind ellipse, as an indication of sea breeze strength, has been identified in April and May at the Campeche Bay (see Fig. 1; Taylor-Espinosa, 2009). Salas et al. (1992) also found significant diurnal spectral peaks of wind in the same area. In the continental region of YP, Soler-Bientz et al. (2010) showed that at the western and northwestern coasts, significant rotation of the wind from the east to the north occurs and they associated their findings with sea breeze circulation. Nonetheless, despite this identification of the western YP region as an area with significant diurnal variability, the spatiotemporal structure of the systems associated with this variability has not been studied, nor has the influence of systems that operate at lower frequencies.

Thus, while previous work has investigated the separate influence of synoptic and local winds on the YP, a characterization of the spatiotemporal interplay of such processes has not been carried out, and therefore a lack of understanding of the associated dynamics exists.

The aim of this work is to conduct a quantitative study to estimate the main spatiotemporal patterns of the surface wind field related to mesoscale and synoptic variability in the YP. This was undertaken through a multivariate statistical technique (CEOF analysis) using 10 years of validated surface wind data from the numerical model NAM run by NOAANCEP (Janjic et al., 2005) (see section 2.2).

\section{Methodology}

\subsection{Study area}

The study area corresponds to the landmass and shallow continental shelf of the YP, which is in eastern Mexico, with an area of $\sim 270000 \mathrm{~km}^{2}$ (Fig. 1). According to the digital elevation model for the region (INEGI, 2013), the physiography of the landmass of YP consists of a relatively "flat" plain in the northern and eastern sides with an average height of $\sim 20$ masl. There are small elevational variations in the center and 
southern sides, such as hillocks and hills, with the El Ramonal hill, at 340 masl, being the most prominent feature (illustrated in Fig. 1). On the western side, there is a slight variation in elevation but with an overall upward gradient from the western coastal plain to the center of YP. This landmass is bordered on the west and north by the GoM, with a wide continental shelf (Campeche Bank $\sim 245 \mathrm{~km}$ in the offshore direction) of average depth $\sim 50 \mathrm{~m}$. On the east, the landmass is bordered by the Caribbean Sea with a narrow continental shelf, and an abrupt slope that falls to average depths of $2000 \mathrm{~m}$ in the Yucatán Basin (INEGI, 2001).

\subsection{Data}

For the CEOF analysis, zonal (east-west) and meridional (north-south) surface wind time series across the offshore and continental regions of the YP were used as inputs. The data were obtained from a 10year (May 2007-May 2017) simulation of the NAM, a nonhydrostatic mesoscale model developed within the Weather Research and Forecasting (WRF) model initiative (Janjic et al., 2005). The NAM simulations are performed by the National Oceanic and Atmospheric Administration's National Centers for Environmental Prediction (NOAA-NCEP) and produce hourly output forecasts, four times per day, but only three-hourly data are archived.

The time series were obtained from daily datasets produced by the NOAA-Air Resources Laboratory (ARL), which contain the first two archived data of each forecast cycle. These files are archived and available in the Real-time Environmental Applications and Display sYstem (READY), a web-based system developed by ARL (Rolph et al., 2017), which provides numerous meteorological datasets to run the HYSPLIT model, an atmospheric fate and transport modeling system (Stein et al., 2015). The NAM ARL-packed format archives were downloaded from READY. Subsequently, using utility programs provided within the HYSPLIT model ("xtrct_grid.exe" and "xtrct_stn.exe"), the NAMgrid domain depicted in Figure 1 and the time series were extracted. The domain extracted corresponds to 2255 grid points. In summary, the data extracted have a spatial and temporal resolution of $12 \mathrm{~km}$ and $3 \mathrm{~h}$, respectively.

The ability of the NAM with the given resolution to reproduce both local and synoptically induced winds in the region must be evaluated by comparison with observations. We are especially interested in wind variability at many frequencies, therefore, prior to the CEOF analysis, power spectra were computed for the model and compared with observations. Given the 12-km horizontal resolution of the model, we can expect that the NAM is barely sufficient to adequately resolve diurnal breeze circulations since the horizontal displacement of these frontal events is typically on the order of tens of kilometers. On the other hand, higher frequency phenomena cannot be present in the 3-h NAM outputs, hence, the patterns of such variability cannot be addressed.

In this comparison, the Pearson correlation coefficient was estimated as

$r=\frac{\sum_{i=1}^{n}\left(x_{i}-\bar{x}\right)\left(y_{i}-\bar{y}\right)}{\sqrt{\sum_{i=1}^{n}\left(x_{i}-\bar{x}\right)^{2}} \sum_{i=1}^{n}\left(y_{i}-\bar{y}\right)^{2}}$

where $x_{i}$ and $y_{i}$ are the model forecast and the observation for one output period, respectively, and $\bar{x}$ and $\bar{y}$ are the averages.

Wind observations were obtained from offshore, coastal and inland meteorological stations. Their location in the YP is depicted in Figure 1 and other details are provided in the SM. A greater number of sites was initially considered, but gaps in the time series (as much as four months) at many sites led us to consider only those sites with at least one-year of continuous observations (September 15, 2012 to September 15, 2013). There are 144 data records per day, consequently, prior to comparison with the NAM data, the observations were interpolated to obtain eight data points per day for all sites. It is important to notice that the 2012-2013 period coincides with a neutral phase of El Niño-Southern Oscillation (ENSO).

\subsection{CEOF analysis}

A CEOF analysis (also known as principal component analysis) was performed to identify persistent structures in the wind field of YP with the strongest horizontal gradients, such as fronts or eddies, that explain the greatest amounts of the variance. The CEOF analysis is a technique widely used in meteorology and oceanography, and has been successfully applied for wind vector fields (Legler, 1983; Ludwig et al., 2004; Pandžić and Likso, 2005; Chung-ru et al., 2008). 
The basic approach for the CEOF analysis implemented in this work involved the application of the eigensolution of the complex representation of the spatial anomalies of the horizontal wind components, $W$ (Legler, 1983).

$W=u+i v$

$W$ was computed for each time step by subtracting from each grid point the spatial average of $u$ and $v$ (zonal and meridional wind component, respectively). This eigensolution yields a better description of the quasi-permanent patterns such as fronts or eddies compared to subtracting the long-term temporal mean from each point of observation (Lagerloef and Bernstein, 1988; Paden et al., 1991). The anomalies are combined into a rectangular data matrix $\mathbf{W}$, with $M$ (2255 grid points) $\times N$ (29 200 records) dimensions . Then a covariance matrix is defined as

$\mathbf{H}=\frac{1}{2 M} \cdot \mathbf{W}^{t} \mathbf{W}$

where the diagonal elements in $\mathbf{H}$ are proportional to the kinetic energy. These elements are joint double-unit variances. Thus, if we want to have unit diagonal elements then the denominator in Eq. (3) must be $2 M$ (Pandžić and Likso, 2005). The eigenvector decomposition for $\mathbf{H}$ is

$$
\mathbf{H} \mathbf{E}=\lambda \mathbf{E}
$$

where $\lambda$ are real eigenvalues and $\mathbf{E}$ is a matrix of complex eigenvectors. Each eigenvalue, $\lambda_{n}$, and its associated eigenvector, $E_{n}$, establish one state of equilibrium of $\mathbf{H}$ and its principal axes of orientation, respectively. A larger $\lambda_{n}$ indicates the dominance of the spatial pattern, defined by

$C_{n}=\mathbf{W} \cdot E_{n}$

The principal component, $C_{n}$, is modulated by $E_{n}$, which describes the temporal variation of the underlying spatial structure $\left(C_{n}\right)$ and may represent an important mode of variability or physical process. The $C_{n}$ and $E_{n}$ were standardized to $\lambda_{n}{ }^{-1 / 2}$ and $\lambda_{n}^{1 / 2}$, respectively, in order to rescale the variance of $C_{n}$ equal to 1 regarding $E_{n}$ in units of $W$ (von Storch and Zwiers, 1999). Finally, North's rule of thumb (North et al., 1982) was applied as a selection rule to decide which modes to keep and which to discard,

$\delta \lambda_{n}=\lambda_{n} \times \sqrt{\frac{2}{a}}$

where $\delta \lambda_{n}$ is defined as the typical error and $a$ the number of independent variables which in this case corresponds to the number of grid points (2255). North's rule of thumb establishes that if the eigenvalue difference between neighbors is larger than the estimated typical error, the eigenvector pattern of the $n$th mode can be considered as non-significantly related to its closest neighbor.

Additional steps were taken in order to better characterize the dominant high or low-frequency process represented by $C_{n}$ and $E_{n}$. First, using a Fourier-based high-pass/low-pass filter (Thomson and Emery, 2014) and considering a cutoff frequency $\left(f_{c}\right)$ of 0.75 cycles per day (cpd), a high-pass and low-pass filtered record of the time series estimated in Eq. (4) were obtained. For the high-pass filter, a response function $\left[W_{h p}\right]$ is constructed with a Hanning windows $(h w)$ of 10 points; the gain is zero for the frequencies $\leq f_{c}$ and one for the frequencies $>f_{c}+h w / 2$. For the low-pass filter, the response function is $\left[W_{l p}=1-W_{h p}\right]$. The frequency response plots obtained are included in the SM. The selected $f_{c}$ is located inside one spectral valley since this separates efficiently the diurnal wind variations from the synoptic circulation $(<0.5 \mathrm{cpd}$; Fiedler and Panofsky, 1970). Hereafter, the term high frequencies or HF is used for the oscillations with a period $<32 \mathrm{~h}$ (related to sea/land breeze circulation, thermal diurnal effects, or others) and the term low frequencies or LF is used for oscillations with a period $\geq 32 \mathrm{~h}$ (related to the synoptic influences, such as cold fronts, tropical systems, or others).

Second, since it is more convenient to describe the temporal evolution of each spatial structure in terms of its amplitude and rotational behavior rather than the real and imaginary components, the amplitude and the phase of the high-pass/low-pass filtered eigenvectors were estimated, where the phase is represented in terms of normalized radians from -1 to $1\left(-180\right.$ to $\left.180^{\circ}\right)$. MATLAB R2017a was used to perform the CEOF analysis and the code was developed in-house. 
2.4 Spectra and cross spectra of wind observations In order to aid the interpretation of the spatiotemporal patterns of variability, spectra and cross spectra of wind observations made at weather stations at locations depicted in Figure 1 were computed for the one-year period from September 15, 2012 to September 15, 2013. These spectra are provided in the SM and will be referenced in the main body of the paper when necessary.

\section{Spatiotemporal patterns of variability}

This section analyzes the spatiotemporal patterns of wind imposed by different phenomena around the YP using output from the NAM. A first step in this objective is to evaluate the model performance by comparing its results with observations. Model vs. observed data were compared using the Pearson coefficient and the power spectral density (PSD). The Pearson coefficient had an average over all YP sites of 0.68 and 0.65 for zonal and meridional winds, respectively. These values can be compared with Pearson coefficient values obtained between QuikSCAT satellite estimations and the National Data Buoy Centre measurements at $85.9^{\circ} \mathrm{W}, 25.9^{\circ} \mathrm{N}$, which have values of 0.91 and 0.91 for zonal and meridional wind, respectively (Piolle and Bentamy, 2002). Despite the modest correlation of NAM data, the coefficients estimated are considered as an indication of reasonable model forecast because of its greater temporal resolution ( $3 \mathrm{~h}$ ) than QuikSCAT satellite estimations ( $24 \mathrm{~h})$.

In addition to an overall assessment of the model (i.e., Pearson coefficient), it is of special interest to assess how well the NAM reproduces the dominant frequencies of oscillation of wind observations in YP. For the purpose of comparison, Figure 2 shows the PSD between modeled and measured wind; the length of the window used in the spectra computations (M) is considered to be accurate to represent the low-frequency energy, which in this case is 1024 data points equivalent to 128 days. It can be seen from this figure that the NAM is consistent with the main patterns of the observed wind spectra for low and high-frequency oscillations. This is true for the power spectra of the western, northern and eastern coasts of the YP for both horizontal wind components. Some differences can be seen, such as a modest overestimation of the PSD at the western and eastern coasts
(CAM and $\mathrm{CNC}$ ) in the meridional LF wind, and a slight underestimation at the northern coast (SIS) in the zonal LF wind. In all cases, the model wind spectral peaks coincide with observations within the confidence level, including the diurnal band related to the sea breeze circulation. Therefore, despite the model resolution is a limiting factor, the temporal patterns of sea/land breezes are adequately captured.

\subsection{Spatial behavior of average winds in the Yuca- tán Peninsula}

Synoptic processes in the region such as cold fronts occur most commonly from October to March (DiMego et al., 1976; Henry, 1979) and other weather systems from the east and south are more active in summer (tropical waves and tropical cyclones). Sea breezes occur all year long but tend to have a peak during April and May (Taylor-Espinosa, 2009). The effects of these phenomena on the seasonality of the time averaged wind patterns can be observed in Figure 3a, b. In order to accommodate the seasonality of these phenomena, the October to March period is treated separately from the period April to September (hereafter, Oct-Mar and AprSep, respectively).

During the months with periodic cold front incursions, the average wind field in YP (Fig. 3a) shows a greater northerly component, whereas for a more tropical-dominated weather (Apr-Sep, Fig. 3b), the average winds are more easterly. Another distinctive feature between the average wind patterns is that during the cold front season the wind magnitude is higher over the offshore region of the YP than during Apr-Sep. During this later period, the average surface wind field is less unidirectional because it has a slight northeasterly tendency over the western shelf.

The computed variance of the low $(\geq 32 \mathrm{~h}$ ) and high-pass $(<32 \mathrm{~h})$ filtered zonal and meridional winds from the NAM can be used to provide insights about the spatial distribution of the phenomena that affect the average wind field patterns. For instance, in Figure 3c, d, the variance from Oct-Mar of the low-pass filtered horizontal components is depicted, and in Figure $3 \mathrm{~g}$, h, the same statistic for the period Apr-Sep is shown. These results show that most of the variability is present in the meridional component during the cold front season and it is located at the northwestern and northeastern shelf of YP, 
a) OBS vs NAM coastal sites power spectra of zonal wind component
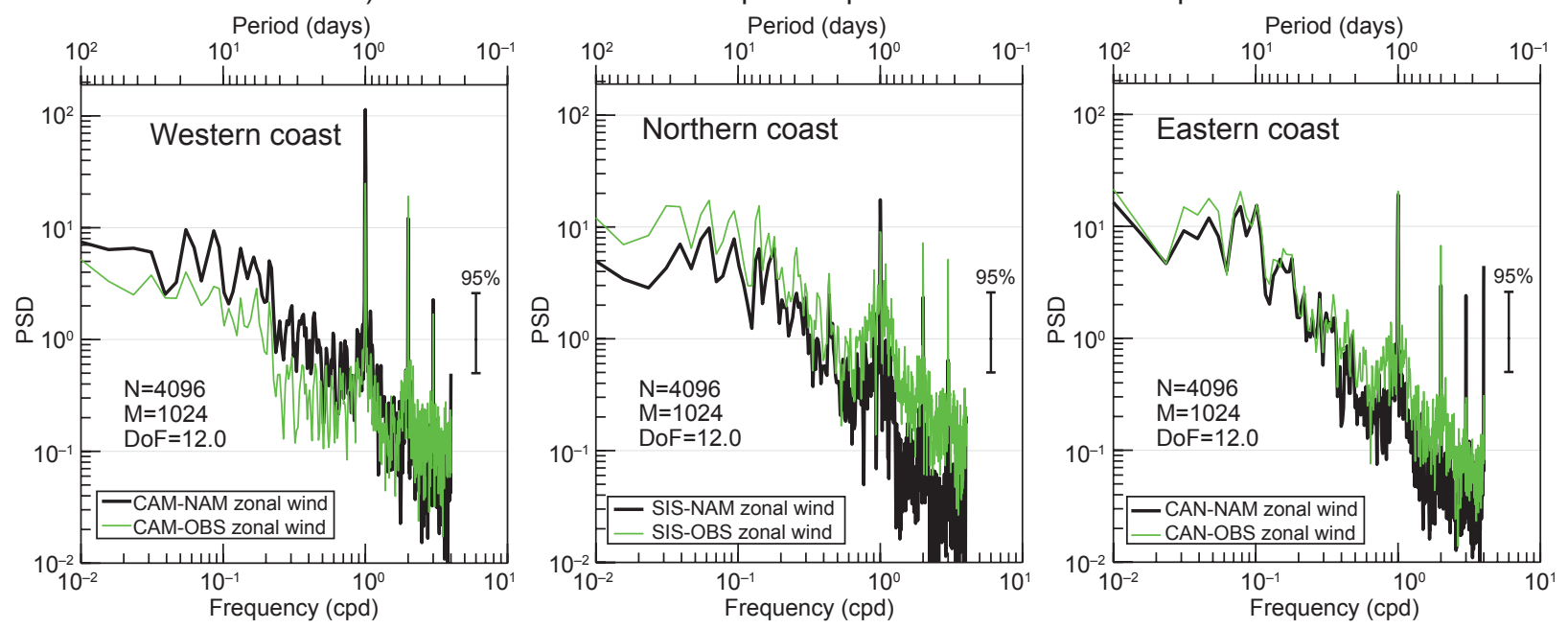

b) OBS vs NAM coastal sites power spectra of meridional wind component
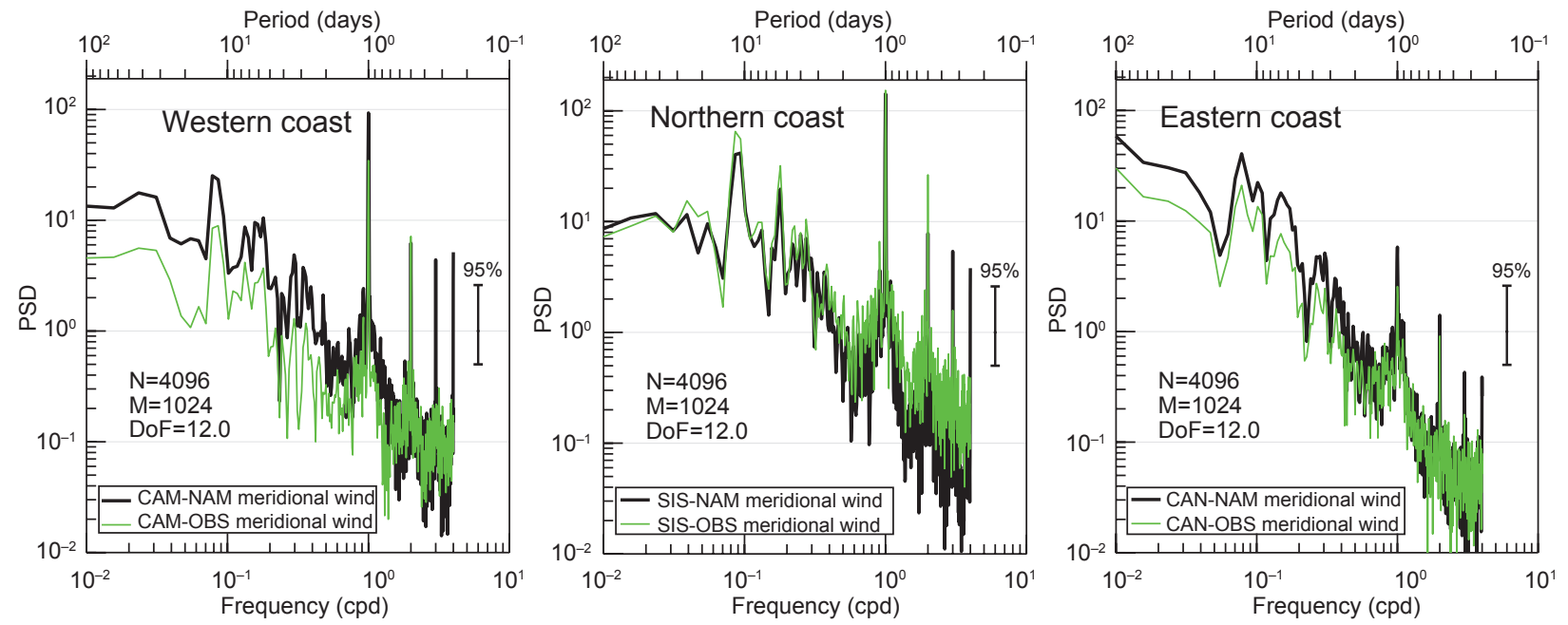

Fig. 2. Power spectra of (a) zonal and (b) meridional wind for the NAM data (black line) and the observations (green line) at three coastal sites in Fig. 1 (CAM, SIS, CNC). The variables in each graph (N, M, DoF) represent the specifications for power spectrum computing (see SM).

diminishing equatorward over the inland landmass. This spatial behavior indicates that the synopticity is higher from Oct-Mar presumably attributed to cold fronts. The greater meridional low-frequency energy of all the power spectra estimated from observations (Fig. 2 and SM) reinforces this idea. Also, the co-spectra of the LF-measured winds has the highest shared-energy in the northernmost oriented sites (PER-SIS), presumably showing stronger cold front influence (see SM).
On the other hand, Figure 3e, f, shows the highpass filtered zonal and meridional wind variance from Oct-Mar, respectively, and Figure 3i, j, shows analogous results for the Apr-Sep period of more tropical influence. The figure shows that HF winds predominate from Apr-Sep in a well delineated area over the western shelf. This can also be seen when examining the spectra of observed wind from coastal and offshore sites, where the diurnal peak gets increasingly important towards the west (Fig. 2 
October to March

(a) Surface wind field average

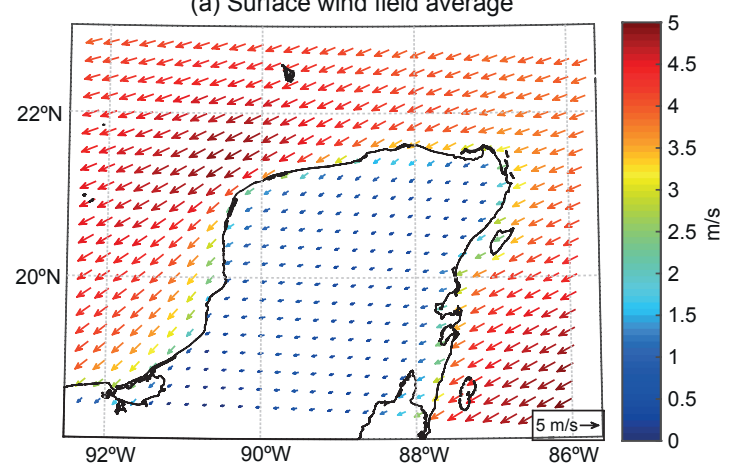

(c) $u$ low-frequency $\sigma^{2}$

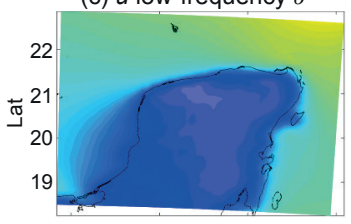

(e) $u$ high-frequency $\sigma^{2}$

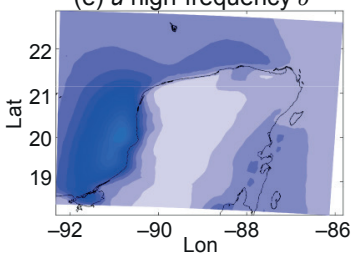

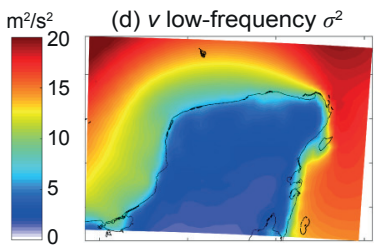

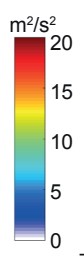

(f) $v$ high-frequency $\sigma^{2}$

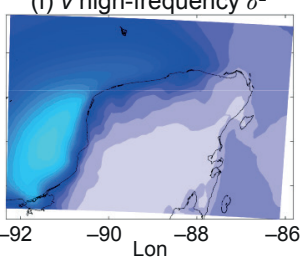

April to September

(b) Surface wind field average

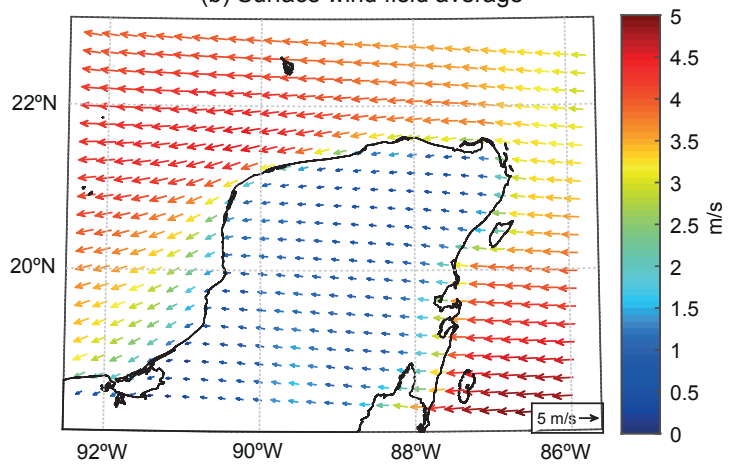

(g) $u$ low-frequency $\sigma^{2}$
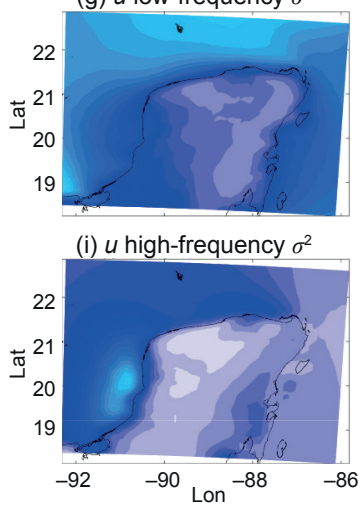

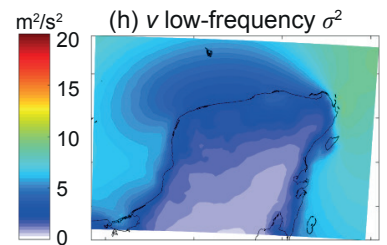

$\mathrm{m}^{2} / \mathrm{s}^{2} \quad$ (j) $v$ high-frequency $\sigma^{2}$
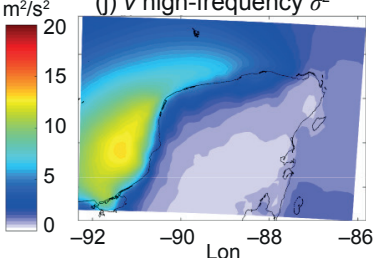

Fig. 3. Descriptive statistics of the surface wind field of the YP derived from the NAM. Surface wind field average from (a) Oct-Mar and (b) Apr-Sep. Variance from Oct-Mar of (c) LF zonal, (d) LF meridional wind, (e) HF zonal and (f) HF meridional wind. The same variance from Apr-Sep: (g), (h), (i) and (j).

and SM). The meridional component has higher variance, suggesting that the diurnal rotation of the offshore winds in the western shelf is more eccentric from north to south. All the above indicates that the slight northeasterly component over the western shelf observed in the average wind field (Fig. 3b) is caused by a diurnal deflection of the wind field from Apr-Sep that might be related to sea breeze activity. Notice in Figure $3 \mathrm{f}$ that this deflection is reduced by a factor of $\sim 2$ from Oct-Mar when sea breezes are also reduced (see section 3.2.2).

We considered it adequate and practical to maintain throughout the paper the separation between the cold front season and months of a more tropical influence for the CEOF analysis. Section 3.2 describes the results for the months with periodic cold front incursions (Oct-Mar) and section 3.3 for the more tropical dominated weather (Apr-Sep).

\subsection{Analysis of the cold front season variability (Oc- tober to March)}

Each mode of variability is represented by the $C_{n}$ spatial structure that is modulated by the $E_{n}$ time series. Therefore, we will refer to the first with the prefix spatial and to the second with the prefix temporal, when describing the patterns observed for each mode. Each time series (Fig. 4d, e) has an amplitude and phase component, which determine the magnitude and rotational behavior of the vectors (from -1 to 1 in normalized radians $[-180$ to $\left.180^{\circ}\right]$ ), respectively. When the temporal phase is equal to 0 , the direction of the vectors will be as represented in the spatial structures shown in Figure 4a, b, c; a negative phase shift indicates a clockwise rotation of the vectors of such spatial structures, while a positive shift corresponds to counterclockwise rotation. 
In Table I the explained variance is presented for the first three modes of variability estimated for Oct-Mar. These modes account for $79.1 \%$ of the variability and the eigenvalue difference between neighbors is larger than the estimated typical error. The remaining variability $(20.9 \%)$ is distributed on 14557 more modes. However, none of these were associated with a specific physical process, so they are not considered further here.

In Oct-Mar season the LF processes (Table I) prevail and mode 1 , explaining $45.1 \%$ of the variance, is the dominant. We were able to achieve a better comprehension of the dominant behavior represented by each mode by jointly analyzing their HF and LF temporal variation and their interplay with the other modes. Hence, throughout this section (and section 3.3) both HF and LF behavior is described.

The temporal variability is partly described using the time series from October 2012 to March 2013 (same period of the observations described in section 2.2), in order to achieve a close examination of the amplitude oscillations and phase shifts (i.e., Fig. 4d, e, respectively). Some specific events are indicated in the time series to highlight the phenomena represented by the modes. The wind field, anomalies and other environmental variables that take place over YP in each time step of Figure 4d, e (including those of the specific events), as well as the NOAA surface weather analysis for the region (https://www. wpc.ncep.noaa.gov), are shown in an animation made available online at: https:/www.youtube.com/ watch? $\mathrm{v}=\mathrm{CEd} 0 \mathrm{axSgS} \mathrm{k} \& \mathrm{t}=1 \mathrm{~s}$.
Additionally, for a better understanding of the physical processes involved in the modal behavior, the time series of both the cross-shore surface temperature gradient and the cross-shore mean sea-level pressure (MSLP) gradient at the shelf (western, northern and eastern) were estimated (i.e., Fig. 4f, g, h, respectively). For instance, we subtract the temperature or MSLP values of an offshore NAM-grid point at the western shelf (i.e., site "a" represented with a square-shaped marker in Fig. 1) to the values of the nearest coastal NAM-grid point to CAM, which is located perpendicular at $100 \mathrm{~km}$ of the site "a" (not depicted in Fig. 1). The same computation was performed to the northern and eastern shelf, but considering sites "b" and "c" (see Fig. 1), and the nearest NAM-grid points to SIS and CNC, respectively (not depicted in Fig. 1).

In these calculations, the differential daytime heating between a cooler sea and a warmer land is indicated by a negative cross-shore temperature gradient, which in turn creates a positive cross-shore pressure gradient pointing toward the land that triggers the sea breeze. In the nighttime, both gradients might be reversed and, in response, a land breeze circulation is established. A closer examination of the daily reversal of these cross-shore gradients is provided in Figures 6 and 8 of the SM. Moreover, in order to better identify the timing of the processes occurring, the daytime temperature gradients (09:00 to 18:00 LT [UTC-06]) are displayed in red markers and the nighttime temperature gradients (21:00 to 06:00 LT) in blue markers.

Table I. Main modes of variability from Oct-Mar. In the first column the predominant behavior is specified with the letters HF or LF.

\begin{tabular}{lccccl}
\hline Mode & $\lambda$ & $\begin{array}{c}\text { Explained } \\
\text { variance }\end{array}$ & $\Delta \lambda$ & $\delta \lambda$ & $\begin{array}{l}\text { Main process } \\
\text { represented }\end{array}$ \\
\hline $1(\mathrm{LF})$ & 31527.9 & $45.1 \%$ & 13277.6 & 938.9 & $\begin{array}{l}\text { Strong N or NE wind } \\
\text { events associated with } \\
\text { cold fronts passages }\end{array}$ \\
\hline $2(\mathrm{LF})$ & 18250.2 & $26.1 \%$ & 12739.4 & 543.5 & $\begin{array}{l}\text { Strong NW wind } \\
\text { events associated with } \\
\text { cold fronts passages }\end{array}$ \\
\hline $3(\mathrm{LF})$ & 5510.8 & $7.9 \%$ & 1451.6 & 164.1 & $\begin{array}{l}\text { Tropical (around Oct.) or high-pressure systems } \\
\text { (around end-autumn to end-winter) influence }\end{array}$ \\
\hline
\end{tabular}


(a) Mode $1(45.1 \%)$

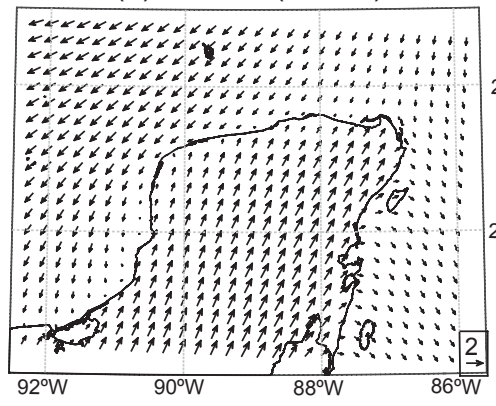

(b) Mode $2(26.1 \%)$

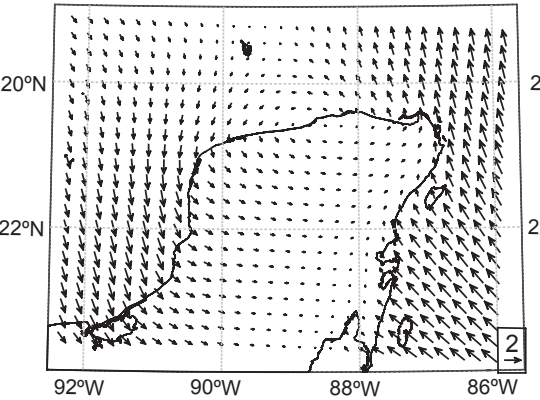

(c) Mode $3(7.9 \%)$

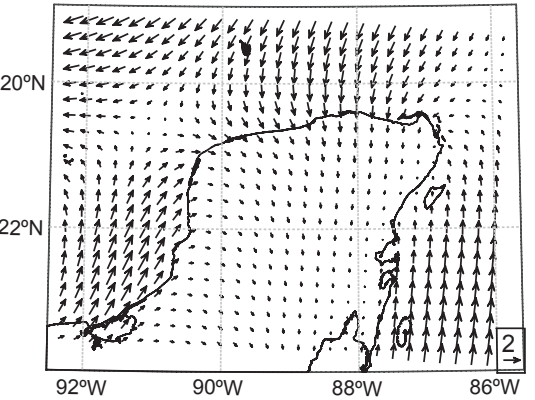

(d) Low-frequency temporal behavior of the modes from October 2012 to March 2013

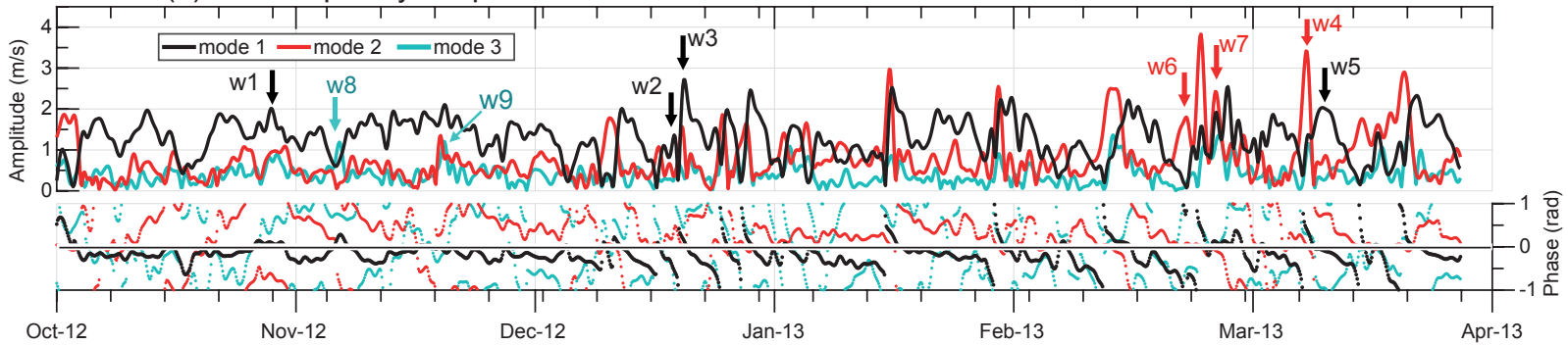

(e) High-frequency temporal behavior of the modes from October 2012 to March 2013

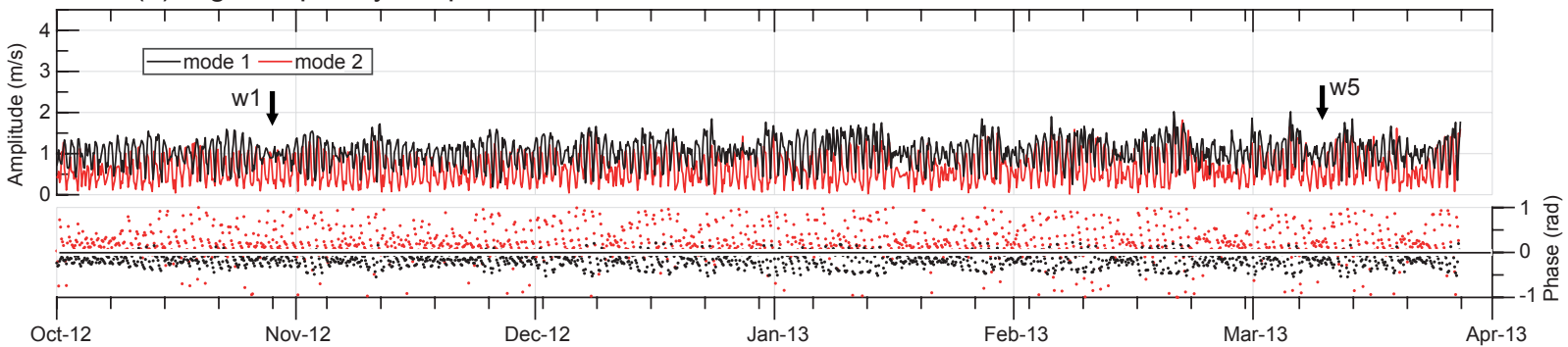

(f) Air temperature and MSLP gradients over the western shelf

2.57
8

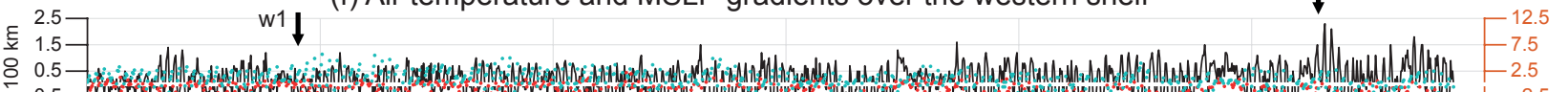

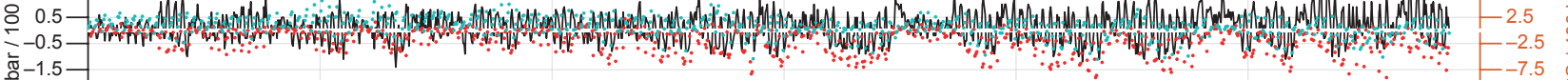

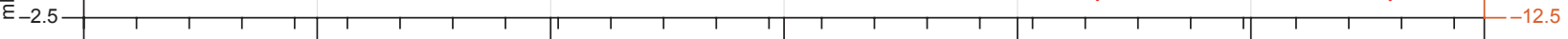

(g) Air temperature and MSLP gradients over the northern shelf
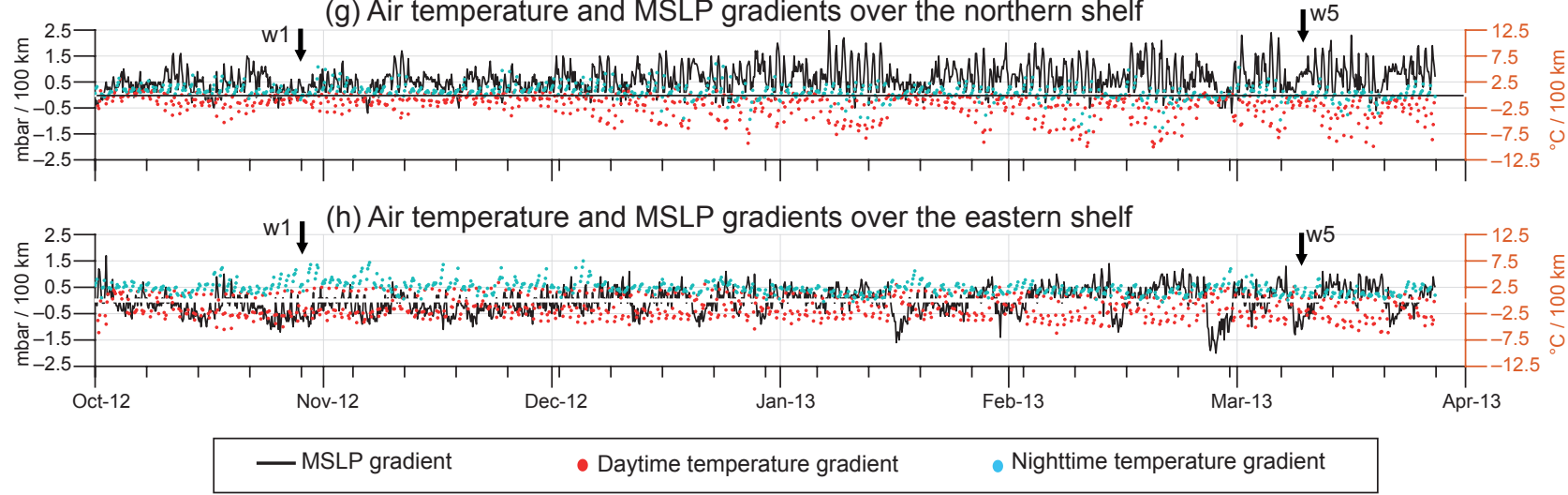

Fig. 4. Spatial structure of (a) mode 1, (b) mode 2 and (c) mode 3 from Oct-Mar. Associated (d) LF and (e) HF amplitude and phase of the eigenvectors. (f, $g$ and $h$ ) NAM model-derived cross-shore surface air temperature and MSLP gradients estimated at the shelf of YP. 
Finally, the interannual scale is also addressed by means of the 10-year time series of Oct-Mar, which is provided in the SM. It will be referenced in the main body of the paper when necessary.

\subsubsection{Influence of northerly winds associated with cold fronts (LF of modes 1 and 2)}

The temporal behavior of mode 1 (and mode 2) during the complete time series shows a prominent LF pattern because of its periodic quasi-weekly oscillations with amplitudes that are about twice those of the HF (compare Fig. 4d and e, respectively).

Thus, the spatial structure of mode 1 depicted in Figure 4a reflects the spatial asymmetry of the northerly winds associated with cold fronts. The stronger northerlies are located over the NNW shelf and the weaker ones over the central-eastern regions of the YP because of the increased surface friction. Evidence of this is found in the computed variance of meridional winds during this season (Fig. 3d). This condition is reached when the leading edge of a cold front crossed the YP (post-frontal influence) or when a cold front shows a less pronounced transition zone in the wind field as it moves across the YP (i.e., when a more northerly-southerly oriented front crosses over the YP).

On the other hand, by examining the spatial structure of mode 2 in Figure 4b, it is clear that the LF winter pulses of this mode (Fig. 4d) represent a greater attenuation of the horizontal wind on the continental landmass of the YP. This occurs due to higher wind shear (i.e., when a more westerly-easterly oriented front crosses over the YP) and land friction effects.

Thus, both mode 1 and mode 2 are representing cold front influences and the greater the temporal amplitude-oscillation of mode 2 , the more abrupt the wind shift of one specific event. Northerly events starting with a marked $\mathrm{N}$ or NE directions can be associated with mode 1 , while events starting with a marked NW direction with mode 2 .

This indicates that the cold front influence during Oct-Mar can be roughly separated into two different temporal patterns: the first one consists of events from $\mathrm{NE}$ (mode 1 at $0^{\circ}$ phase, see event $w 1$ in Fig. 4d, that takes place on October 28, 2012, 15:00 LT), which have a more consistent direction (stable phase) from October to mid-December; and a second more dynamic pattern, with stronger wind events that shift direction abruptly from SE (mode 1 at $\sim-90^{\circ}$ phase; event $w 2$ on December 20, 2012, 03:00 LT) to NE (event $w 3$ on December 21, 2012, 03:00 LT) in the winter months. Sometimes the northerly events start with a marked NW direction (dominance of mode 2 at $0^{\circ}$ phase; event $w 4$ on March 12, 2013, 00:00 LT) and then become NE (mode 1 dominance; post-frontal influence; event w5 on March 13, 2013, 18:00 LT). The NW start of the northerly storms is more common towards the end of the winter. This behavior of mode 2 could be associated with the presence of maritime polar $(\mathrm{mP})$ frontal systems coming from the North Pacific Ocean, which were identified by Henry (1979). These fronts tend to dominate during March and travel in a more eastward direction.

Visual inspection of the model outputs suggest that other cold front related-influences, such as inverted prefrontal troughs occurring in the warm air ahead of the front (Schultz, 2005) and stationary fronts over the YP landmass, are better represented by the LF of mode 2 due the horizontal wind shear generated (for instance events $w 6$ and $w 7$ in Fig. 4d, on February 24, 2013, 03:00 LT and February 28, 2013, 03:00 LT, respectively).

As would be expected, there is interannual variability in the relative temporal behavior. For instance, during 2009-2010 and 2015-2016, the abrupt phase shifts and amplification of mode 1 start earlier, during mid-autumn. In those winters, the mode 2 dominance over mode 1 was also considerable (see SM). This suggests incremented frequency and intensity of cold fronts over the YP. Those years coincide with the warm phase of ENSO and it has been reported that those events (El Niño events) correlate positively with cold front activity in the US-east coast and the Intra-Americas sea (Melo-González et al., 2000; Hirsch et al., 2001) and with northerly events over the southern end of the Isthmus of Tehuantepec (Romero-Centeno et al., 2003).

In their study of the variability of sea winds of the Yucatán Basin-Caribbean Sea, Pérez-Santos et al. (2010) estimated that their winter mode 1 is also associated with northerlies generated by cold fronts. However, the YP landmass was not included in their analysis, so neither the spatial asymmetry of northerlies due to frictional effects of the continent (mode 1 of this study) nor the influence of cold fronts with a more zonal trajectory (mode 2 ) were observed. 
3.2.2 Land and sea breezes during cold front periods (HF of modes 1 and 2)

Even though modes 1 and 2 show a predominant synoptic (LF) flow (Fig. 4a and b, respectively), their associated HF time series also contain a clear diurnal pattern. The periods of large-amplitude oscillations in the LF of mode 1 (Fig. 4d) coincide with periods of small-amplitude oscillations in the HF for the same mode (Fig. 4e). For instance, during the events $w 1$ and $w 5$ in Figure $4 \mathrm{~d}$, the air-temperature gradients over the YP shelf were damped indicating a cooling effect (see Fig. $4 \mathrm{f}-\mathrm{h}$; notice that $w 5$ was a stronger front). Conversely, Figure $4 \mathrm{e}$ shows that the periods of amplification of the HF correspond to periods of little synoptic influence, indicating synchronization of the modes and that the HF are modulated (reduced) by the frontal influence. In the interannual scale, this modulation is noticeable during the seasons of increased cold front activity (for instance, 2009-2010 and 2015-2016; see SM).

This is especially true because under weak cold front influence the cross-shore MSLP gradient between the sea and the landmass will undergo larger daily oscillations, which is a favorable condition for triggering sea breeze and land breeze patterns. Over the western shelf the general tendency is a daily positive/negative MSLP oscillation (Fig. 4f; sea/land breeze pattern); at the northern shelf the oscillation remains more positive (Fig. 4g; sea breeze dominance); and at the eastern shelf, the oscillation is more irregular (Fig. 4h; weak-intermittent breeze). This pattern suggests that the sea/land breeze circulation will be more active over the western shelf. This idea is reinforced by the existence of nighttime cooling (daytime heating) at the western coast observed in Figure 4f, which coincides with a seaward (coastward) wind flow over the western shelf indicated by the spatial structure of mode 1 in Figure 4a (mode 2; Fig. 4b) when the phase of the temporal oscillation is $\sim 0^{\circ}$.

We suggest that the HF oscillations of mode 1 are associated to the nighttime onset of land breezes; and the sea breezes with the HF oscillations of mode 2, which are out of phase behind mode 1 , coinciding with the daytime heating conditions (a closer examination of this behavior is provided in the SM). During periods of low synopticity, land breezes seem to be stronger than sea breezes, since mode 1
HF amplitudes are consistently larger than the ones of mode 2 during the entire 10 -year period analyzed (see SM). We hypothesize that land breezes tend to dominate due to greater land cooling in Oct-Mar.

The spatial patterns of mode 1 (Fig. 4a) and mode 2 (Fig. 4b) show regions where land breezes or sea breezes are of lesser importance during the cold front season. For instance, the amplitude of mode 1 (land breezes) is larger in the northwestern YP shelf, and towards the east its importance diminishes. Mode 2 (sea breezes) seems to lose importance in the northern coast during this period and is more energetic on the western and eastern coasts. The synopticity during the Oct-Mar season affects the spatial amplitude of sea/land breezes, reinforcing the idea that the most prominent features of mode 1 and mode 2 represent cold front influence.

\subsubsection{Tropical and high-pressure systems influence} (LF of mode 3)

Mode 3 accounts for $7.9 \%$ of the variance during Oct-Mar and is only associated with LF behavior. The entire 10-year time series (see SM) shows larger amplitude oscillations during October but this is not a recurring pattern throughout all the periods. For instance, in the season 2009-2010, it is amplified from the end of the autumn to the end of winter.

The greatest pulse of amplitude with a phase near $0^{\circ}$ was on October 22, 2014 (event $w 10$ in Figure SM-5e). In this event, a tropical depression (that later evolved into tropical storm Hanna) was formed over Campeche Bay and moved eastward to the YP. This system generated a wind vector anomaly pattern similar to the spatial amplitude of mode 3 (Fig. 4c), characterized by showing cyclonic circulation in the Campeche Bay area when the associated phase is $0^{\circ}$. Other examples include tropical storms Rina (2011) and Karen (2013). In these relatively rare cases, the LF oscillations of mode 3 were larger than the other. Hence, we suggest that mode 3 (with phase near to $0^{\circ}$ ) represents the (rather limited) influence of tropical systems on YP during months of reduced tropical activity. October is particularly important because it is considered a very active month of the hurricane season (Kimball and Mulekar, 2004; Vecchi et al., 2011).

Events $w 13$ (January 17, 2010) and $w 14$ (January 29, 2017) shown in Figure SM-5e are examples of 
different spatiotemporal behavior. These correspond to the presence of migratory high-pressure systems in the southern GoM associated with cold fronts that crossed the YP on the previous days. Based on this evidence, we suggest that mode 3 with phase $\sim 180^{\circ}$ can also represent anticyclonic circulations. This idea is reinforced by the analysis of the interannual behavior of mode 3. During end-autumn to end-winter this mode seems to be synchronized with the years of an incremented frequency of cold fronts (for instance 2009-2010 and 2015-2016) that display abrupt phase shifts and amplification of the LF of mode 1 that start in mid-autumn.

During October 2012-March 2013, events w9 (November 20, 2012, 09:00 LT) and $w 8$ (November 5, 2012, 15:00 LT) in Figure 4d are examples of cyclonic and anticyclonic circulations, respectively, represented by mode 3 .

\subsection{Analysis for the season with larger tropical in- fluence (April to September)}

The same analysis was made for the months with increased tropical activity in the GoM and the Caribbean Sea. Similarly, the first three modes of variability accounted for $74.2 \%$ (Table II) and the remaining variance was spread along 14495 other modes. Nonetheless, the most prominent features of mode 1 of this season represent a sea breeze (HF) circulation, with similar explained variance than that of mode 1 of Oct-Mar.

In this section, Apr-Sep 2013 time series were selected to display the amplitude and phase-shifts (Fig. 5d, e). Analogous to section 3.2, some specific events are indicated in the time series to highlight the phenomena associated with the modes. The wind field, the anomalies and other environmental variables that take place over YP during Apr-Sep 2013 (including those of the specific events indicated in Fig. 5d, 5e) are shown in an animation made available online at: https://www.youtube.com/watch?v=ahRI$\mathrm{WpSzVic} \& \mathrm{t}=333 \mathrm{~s}$. To examine the interannual behavior, the 10-year time series is also included in the SM. We will first discuss the LF behavior in this season to follow a similar order to section 3.2.

\subsubsection{Cold fronts and tropical systems (LF of mode 2 and mode 1)}

In this section we focus on the behavior of the LF of modes 2 and 1, addressing both modes together to better understand the physical process involved. Both LF time series of mode 2 and 1 explain two different dynamics during Apr-Sep period (Fig. 5d).

The first behavior is related to remnant cold fronts passing from April to mid-May. Although the equatorward propagation of cold fronts is hindered (the percentage of cold fronts that undergo frontolysis in the GoM in Apr-Sep is 51-100\%, compared to $17-51 \%$ in Oct-Mar [Henry, 1979]), some fronts can cross the YP reaching the Caribbean Sea, mainly from April to mid-May. This pattern is represented by pronounced changes in phase $\left(\sim 180^{\circ}\right)$ of mode 2 but it also includes overlapping amplitude oscillations of modes 2 and 1 (for instance, events $s 1$ and $s 2$ in Fig. 5d, on April 5, 2013, 09:00 LT). We believe that this overlapping could be an artifice of the analysis due to the short period included for solving cold front variability which is properly described in the previous section.

Table II. Same as Table I but from Apr-Sep.

\begin{tabular}{lccccl}
\hline Mode & $\lambda$ & $\begin{array}{c}\text { Explained } \\
\text { variance }\end{array}$ & $\Delta \lambda$ & $\delta \lambda$ & Main process represented \\
\hline $1(\mathrm{HF})$ & 26160.5 & $42.4 \%$ & 11889.8 & 779.1 & $\begin{array}{l}\text { Sea breeze circulation accentuated over the } \\
\text { western shelf }\end{array}$ \\
\hline $2(\mathrm{LF})$ & 14270.7 & $23.1 \%$ & 8880.4 & 425.0 & $\begin{array}{l}\text { Cold fronts (around April to mid-May) or } \\
\text { tropical systems influence (around mid-May } \\
\text { to September) }\end{array}$ \\
\hline $3(\mathrm{HF})$ & 5390.3 & $8.7 \%$ & 1170.7 & 160.5 & $\begin{array}{l}\text { Land breeze circulation accentuated over the } \\
\text { western shelf }\end{array}$ \\
\hline
\end{tabular}


(a) Mode $1(42.4 \%)$

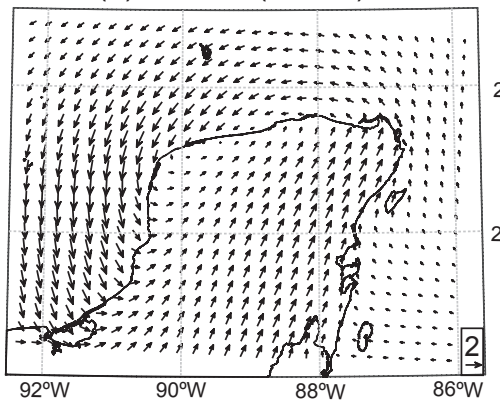

(b) Mode $2(23.1 \%)$

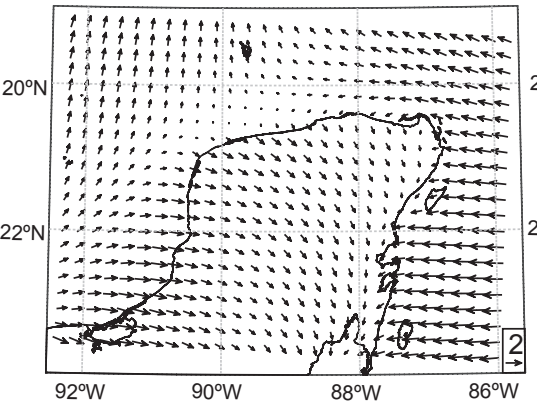

(c) Mode $3(8.7 \%)$

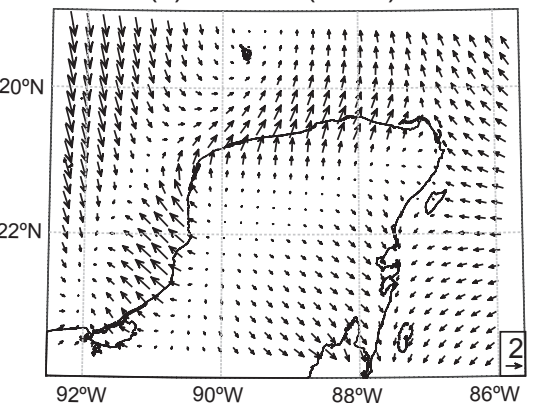

(d) Low-frequency temporal behavior of the modes from April to September 2013

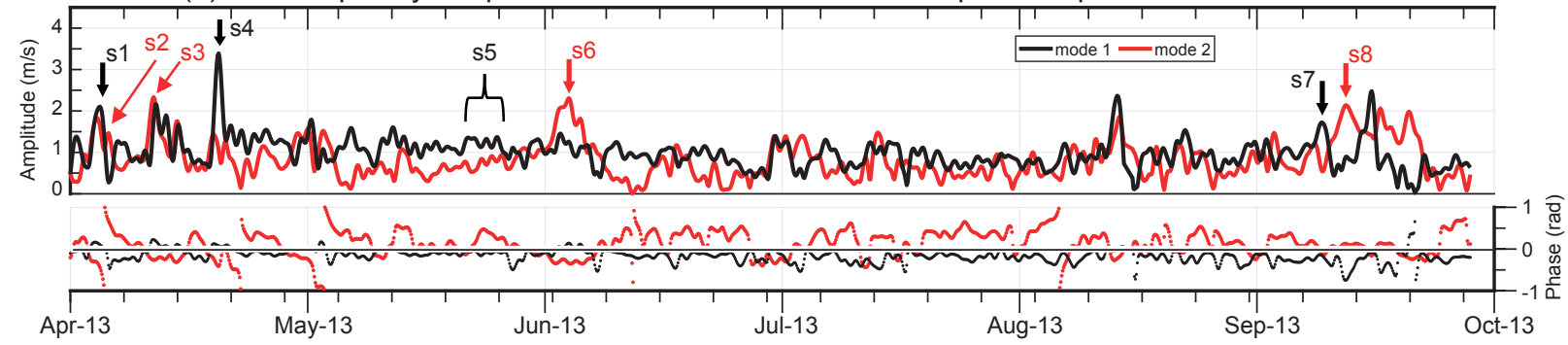

(e) High-frequency temporal behavior of the modes from April to Septeber 2013

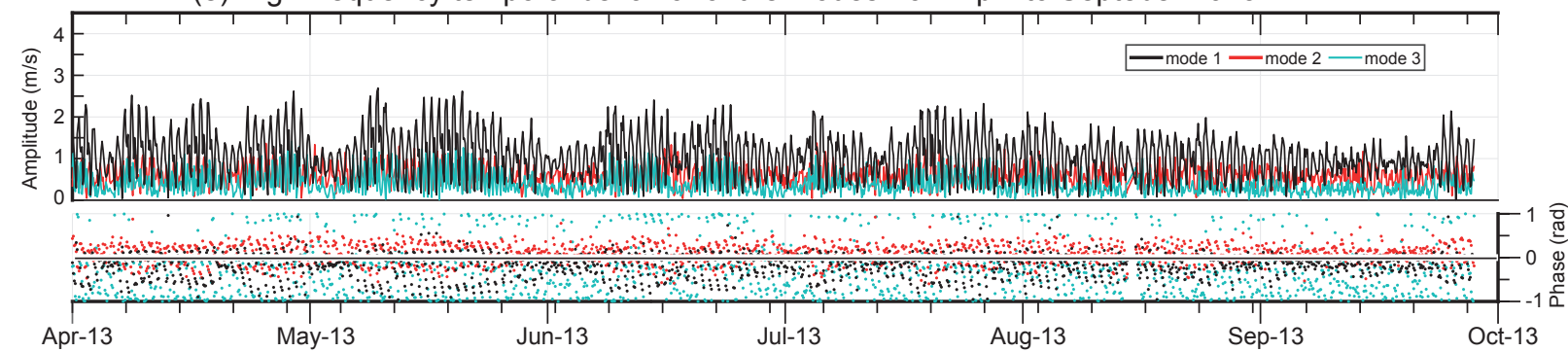

(f) Air temperature and MSLP gradients over the western shelf

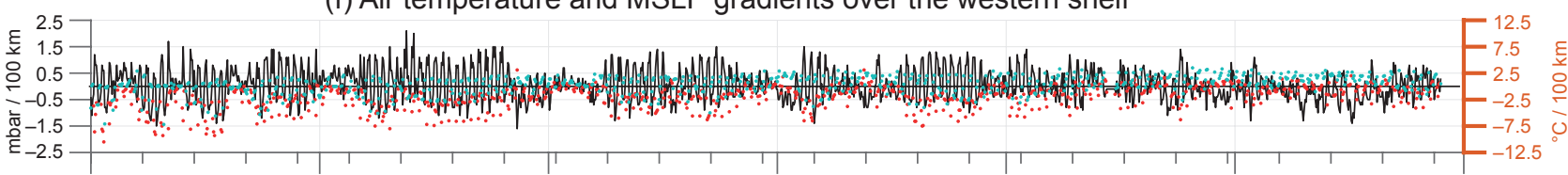

(g) Air temperature and MSLP gradients over the northern shelf

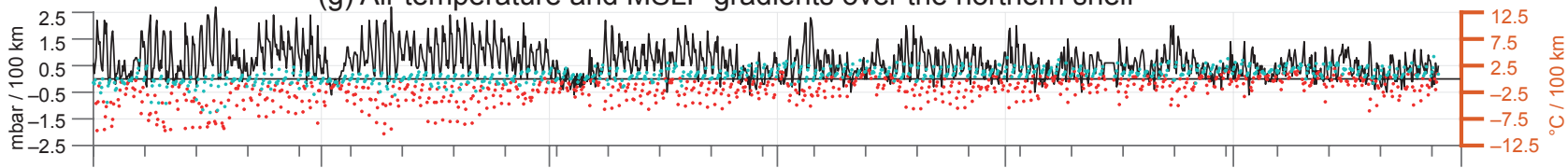

(h) Air temperature and MSLP gradients over the eastern shelf

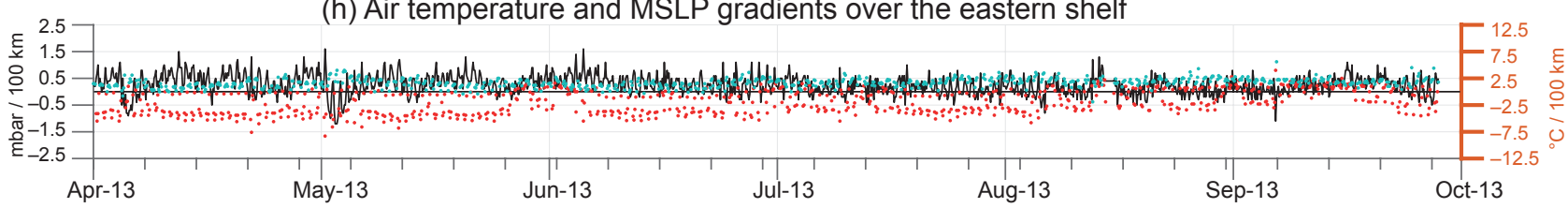

\begin{tabular}{lll|}
\hline - MSLP gradient $\quad$ Daytime temperature gradient $\quad$ Nighttime temperature gradient \\
\hline
\end{tabular}

Fig. 5. Same as in Figure 4 but for April to September 2013. 
A different set of phenomena involves weaker systems that undergo frontolysis in the YP, or that are returned from YP to the GoM as warm fronts (events $s 4$ and $s 3$ in Fig. 5d, on April 20 and April 13, 2013, respectively). These are represented by amplitude oscillations of mode 2 overlapping with mode 1 , but not with a pronounced phase shift of mode 2 . According to this criterion, in April and May of 2011 no front penetrated beyond the YP (see SM). Indeed, the cold front season of October 2010-March 2011 was of lowered frontal influence as it is shown in the SM. Thus, less pronounced changes of the phase of mode 2 in the first two months of the time series (April and May) may represent the onset of tropical activity during the Apr-Sep season.

From mid-May, the amplitude oscillations of mode 2 are characterized by less abrupt changes of phase with predominantly mild counterclockwise shifts (cyclonic) over a quasi-weekly basis that represent the presence of tropical systems (depressions, tropical storms, etc.) over the GoM or Caribbean Sea that exert influence over the YP. The change of phase of mode 2 is due to the position and trajectory of the system with regard to the YP, which can be meridional (clockwise shift; event $s 6$ in Fig. 5d, June 5, 2013) or zonal (counterclockwise shift; event $s 8$ on September 14, 2013).

When the tropical systems make landfall on the continental landmass of YP (or developing into lows on YP, for instance, event 57 in Fig. 5d, September 11, 2013) a response of the LF of mode 1 is observed with an associated phase $\sim 0^{\circ}$. This might be attributed to anomalous cyclonic circulation on the continent not included into the spatial pattern of mode 2 . The greatest tropical influence over the YP landmass during the entire time series corresponds to hurricane Dean, which made landfall on the eastern coast of YP as a category 5 system on August 21, 2007 and is shown by the largest LF amplitude oscillation of mode 1 (see SM).

On the other hand, the influence of tropical waves moving westward in the trade belt seems to be better associated with mode 1 by means of small periodic LF amplitude-oscillations (event $s 5$ in Fig. 5d, from May 23 to 26, 2013). All these findings are comparable with the influences described on the Yucatán basin-Caribbean Sea by Pérez-Santos et al. (2010), which are tropical waves, low-pressure systems and hurricanes (first, second and third modes of variability, respectively). However, as will be described in the next section, such influences would become less dominant over the YP, if we consider the variability imposed by the sea breezes.

The interannual amplitude of the tropical influences on the YP shown in the SM (mid-May to September) indicates that 2009, 2014 and 2015 were seasons of lowered activity. For 2009 and 2015, they coincide with El Niño events, characterized by inhibiting tropical cyclogenesis in the North Atlantic (Colbert and Soden, 2012). For the case of 2014, an anomalous vertical wind shear pattern over the Caribbean Sea and much of the tropical Atlantic from August to the end of the season, in combination with an anomalous sinking motion at lower latitudes in the tropics, suppressed tropical cyclogenesis (Pasch, 2015).

\subsubsection{Sea and land breezes accentuated over the western shelf (HF of mode 1 and mode 3)}

The HF oscillations of mode 1 are clearly dominant over the LF in the YP from Apr-Sep with a clear sinusoidal behavior with diurnal frequency (Fig. 5e). This is opposite to what was observed during the cold front season. Comparison of Figure 5d, e, clearly shows that LF oscillations during this season (cold fronts and tropical systems) are not strong enough to damp out the amplitude of the HF of mode 1. By examining the spatial pattern of this mode (Fig. 5a), it is notorious that it represents a sea breeze structure on the YP, blowing with greater intensity toward the west and northwest of the peninsula. This pattern is consistent with the deflection of the average wind field in this region from Apr-Sep (Fig. 3b) analyzed in section 3.1.

The temporal variability of sea breezes (mode 1) exhibits longer term modulations (seasonality). A consistent pattern of greater amplitude oscillations from April to May is observed in most years (see SM), with a daily rotational pattern in a clockwise direction from $\sim 0^{\circ}$ (landward winds) to $\sim 180^{\circ}$ (seaward winds) which allows the sea breeze phenomena to be established. During the next months, the amplitude and phase are decreased. This can be understood as representing the diminished strength of sea breezes (and land breezes).

However, there are some exceptions in the interannual behavior (2007, 2012, and 2014). For instance, 2014 shows larger amplitude oscillations during June and July. This pattern can be explained by increased cold front influence in April and mid-May of that 
year (see SM; notice more pronounced changes in phase of LF mode 2 in $\sim 180^{\circ}$ ) that reduced sea breeze intensity.

Mode 3 from Apr-Sep is only associated with HF phenomena (Fig. 5e). Mode 3 phases also show important shifts in a clockwise direction $\left(\sim 180^{\circ}\right)$ which are related to the dynamics of mode 1. During daytime, when the sea breeze blows (mode 1 , phase $\sim 0^{\circ}$ ), mode 3 is shifted to $\sim 180^{\circ}$. At nighttime the land breeze gains strength (mode 1, clockwise phase shift), and mode 3 is shifted back to $\sim 0^{\circ}$. A closer examination of these phase shifts is provided in the SM. Thus, the nighttime wind structure represented by mode 3 can be associated with land breezes over the western and northern YP, which are of higher intensity at the western shelf due to the convergence zone indicated by its spatial pattern (Fig. 5c). It is also clear that a seasonal pattern exists, with the land breeze reducing its amplitude towards the end of each summer (September) in all years (see $\mathrm{SM}$ ). Sea breezes have a larger amplitude (by a factor of $\sim 2$ ) than land breezes during this period.

Thus, during the period of increased tropical influence (Apr-Sep), the sea/land breeze circulation will be occurring more intensely over the western shelf. Cross-power spectral density estimations of wind observations (see SM) between ARC-CAM reinforce this idea, as it indicates that the diurnal oscillation is the dominant frequency over the western shelf. This behavior confirms the insights by Taylor-Espinosa (2009), Gille et al. (2003) and Soler-Bientz et al. (2010) about the spatial distribution of diurnal variability on the YP and its associated phenomena. The greater sea breeze activity during April to May found in this analysis is consistent with the findings during the same period for the Campeche Bay by Taylor-Espinosa (2009).

According to Gille et al. (2003), poleward from $15^{\circ}$, the offshore extent of the sea breeze shows a strong seasonal cycle with the signal largely disappeared in winter. We concur with this spatiotemporal behavior, since the temporal amplitude oscillation of sea breezes in YP is higher from Apr-Sep (by a factor of $\sim 2$ ) than those from Oct-Mar (compare Fig. 5e and Fig. $4 \mathrm{e}$, respectively). In this regard, during the cold front season (Oct-Mar), our results suggest that the amplitude of nighttime land breezes is slightly higher than sea breezes (by a factor of $\sim 0.3$ ), which can be related to very active land cooling effects as it was shown in Figure 4f. The contrast in the seasonal cycle of sea/land breezes is also evident in the spatial amplitude of the main modes, since in Apr-Sep the local circulation is well represented (modes 1 and 3 ) while in Oct-Mar the pattern is basically synoptic (modes 1 and 2; see section 3.2.2). Further examination about the underlying mechanism for the development of sea breezes and land breezes throughout the seasonal cycle in YP is required, and our findings can provide a reference framework for future studies.

\subsubsection{Along-peninsula sea breeze circulation (HF of mode 2)}

The HF variability of modes 1 and 3 shows a very weak sea/land breeze circulation at the eastern shelf. Indeed, in the cross-power spectral density estimations, the diurnal co-oscillation at this region is below the confidence level, even though the coupled pair of sites used for this calculation (MUJ-CNC) are only $12 \mathrm{~km}$ apart (see SM). This suggests that the horizontal thermal gradients over the eastern shelf are usually not strong enough to trigger the local circulation. An explanation for this behavior is the cooling effect of the trade winds that may be stronger in the easternmost of the YP since it is more exposed to such influence. This idea is reinforced by the behavior of the air temperature and MSLP gradients between two sites of the eastern shelf, which do not show a daily systematic change and are lower compared to the other regions of the YP shelf (compare Fig. 5h, f and g). These findings are comparable with the work of Pérez et al. (2018) on the Colombian Caribbean coast, who hypothesize that the lack of sea breezes at their easternmost site could be due to the strong trades.

Nevertheless, our results indicate that some local circulation can be expected at the eastern shelf. By examining the spatial structure of mode 2 in Figure $5 \mathrm{~b}$ we can observe a landward wind pattern (sea breeze) over both western and eastern coasts. Visual inspection of the 10-year time series indicates that a daytime oscillation of the HF mode 2 of higher amplitude than the HF mode 1, is associated with an unusual sea breeze circulation encompassing the entire YP shoreline. Based on this criterion (higher diurnal oscillation of HF mode 2), our results indicate that this phenomenon occurs mainly in September (3.4 September-average events, against 2.6 monthly-average 
events), but may occur during all the season (for instance, see May 6, 2013, 15:00 LT, in the animation provided). This temporal behavior can be partly explained due to the existence of lowest wind magnitudes between the months of September and October on YP (Soler-Bientz et al., 2010), which in turn might be associated with the weakening of the trade winds over the Caribbean Sea from summer to fall (Chang and Oey, 2013).

The inland progression of the sea breezes formed along the coastlines of the peninsula might result in the collision of the fronts at the center of the landmass (Simpson, 1994). However, the landmass extent of YP is too wide ( $>150 \mathrm{~km})$ to allow the convergence of sea breezes (Xian and Pielke, 1991). We must recognize that the extension of the inland penetration of opposing sea breezes cannot be addressed with the results derived from the present study. In narrower peninsulas, such as Baja California (Turrent and Zaitsev, 2014) and Florida (Blanchard and López, 1985) the regular collision of opposing sea breeze fronts is an important process, which is more dominant during the summer.

On the interannual scale, 2009 was the year of higher activity (amplitude) of the HF of mode 2 (see SM). We hypothesize that this can be related to a weakening of the NASH (and the trade winds) along with lowered tropical activity related to an El Niño event (moderate in 2009), since such influences correlate negatively with the warm phase of ENSO (Colbert and Soden, 2012). However, other experiments should be conducted to prove this hypothesis.

\section{Conclusions}

A quantitative study to assess the spatial and temporal variability of surface winds related to synoptic and mesoscale phenomena in the Yucatán Peninsula (YP) was carried out. The time series were separated in two seasons, one from October to March (cold front season) and the other from April to September (tropical influence), to represent the dominant wind phenomena. Two separate CEOF analyses were made, one for each season.

From October to March cold fronts (low frequencies) dominate the wind variability, and have two main patterns (modes) on the peninsula. The first mode consists of strong wind events from NE which occur predominantly from October to the end of autumn and have a more consistent direction (stable phase). The second mode has a more dynamic pattern, which predominates during winter months, with events that shift direction from NW to SE. Some interannual variability exists in these patterns. For example, during El Niño seasons, abrupt phase shifts and amplification of the first mode starts during mid-autumn, apparently linked to increased frequency of cold fronts. Cold fronts have a profound influence on sea breeze and land breeze activity, greatly reducing and modulating these events. Land breezes are stronger and occur more often on the western shelf but are relatively scarce on the northern and eastern shelf. Sea breezes on the other hand, although less intense, are also more energetic on the western shelf. The influence of tropical systems in this season, although smaller, is noticeable (low frequencies; third mode), mainly during October.

For the period of increased tropical influence (April-September), wind variability is largely dominated by sea breezes (high frequencies; first mode), with land breezes being less active than during the cold front season (high frequencies; third mode). April-May is generally the period of largest amplitude of sea breezes. During seasons of increased cold front passages (for example 2014, represented by the low frequencies of the second mode), sea breezes cannot reach their maximum intensities during April-May. Sea/land breeze circulation also dominates over the western shelf as observed during the cold front season. Synoptic processes in this period exert a milder influence on wind variability except when these systems (depressions, storms, hurricanes) are in close proximity. The spatial pattern of their influence on the wind field depends primarily on the position and trajectory of the tropical system with regard to the YP. There is no fixed pattern, but counterclockwise shifts in the wind (cyclonic phase shifts) are the most commonly represented pattern by the low frequencies of the second mode.

The spectra and coherence of observations of wind variability at weather stations confirm the model-based findings that the diurnal oscillation in the wind (sea breezes) is greatly reduced at the eastern shelf of the peninsula. We observe that the horizontal thermal gradients are not strong enough to trigger this local circulation on the east, due to the 
cooling effect of the trade winds which are stronger over the easternmost YP. Nonetheless, sea breezes can indeed occur occasionally on the eastern shelf in a sea breeze structure encompassing the entire YP shoreline (seen in the high frequencies of the second mode of April-September).

The results of this work are relevant for atmospheric dispersion, local climate, wind wave generation and beach morphodynamics, among others.

\section{Acknowledgments}

The authors gratefully acknowledge the Mexican National Council for Science and Technology (CONACYT, acronym in Spanish) for the funding provided for this study. We also acknowledge NOAA's National Centers for Environmental Prediction and the NOAA-Air Resources Laboratory for making available the NAM model outputs. We also appreciate the surface wind observations provided by the Mexican National Water Commission (CONAGUA, Spanish acronym), and by the Mexican Navy (SEMAR). Finally, we are grateful to the anonymous reviewers of this document for their valuable comments and suggestions that benefited the work.

\section{Supplementary material}

Auxiliary information to aid the interpretation of the spatiotemporal patterns of wind variability is available at: https:/www.revistascca.unam.mx/atm/SupplementaryMaterial/52713-Cahuich-SupMat.pdf, consisting of: (1) details of the network of weather stations selected for model comparison; (2) spectra and cross-spectra of surface wind observations; (3) 10-year time series of the wind modal temporal behavior (2007-2017) for both cold front season and larger tropical influence season; (4) close examination of sea breeze and land breeze amplitude oscillations and phase shifts; and (5) the frequency response of the high-pass/low-pass filter described in section 2.3.

\section{References}

Berlyand ME. 1991. Prediction and regulation of air pollution. Atmospheric and Oceanographic Sciences Library, 14. Springer Science and Business Media, 312 pp. DOI: 10.1007/978-94-011-3768-3
Blanchard DO, López RE. 1985. Spatial patterns of convection in south Florida. Monthly Weather Review 113:12821299. DOI: $10.1175 / 1520-0493(1985) 113<1282$ :SPOCIS $>2.0 . \mathrm{CO} ; 2$

Bornstein RD, Thompson WT. 1981. Effects of frictionally retarded sea breeze and synoptic frontal passages on sulfur dioxide concentrations in New York City. Journal of Applied Meteorology 20:843-858.

DOI: 10.1175/1520-0450(1981)020<0843:EOFRS$\mathrm{B}>2.0 . \mathrm{CO} ; 2$

Chang YL, Oey LY. 2013. Loop Current growth and eddy shedding using models and observations: Numerical process experiments and satellite altimetry data. Journal of Physical Oceanography 43(3):669-689.

DOI: 10.1175/JPO-D-12-0139.1

Chung-ru H, Zhe-wen Z, Chun-yi L, Nan-jung K, Chih-chung T. 2008. Wind field variations in the tropical Pacific Ocean from satellite scatterometer data. Geographic Information Sciences 14:120-123. DOI: 10.1080/10824000809480647

Colbert AJ, Soden BJ. 2012. Climatological variations in North Atlantic tropical cyclone tracks. Journal of Climate 25:657-673. DOI: 10.1175/JCLI-D-11-00034.1

Davis RE, Hayden BP, Gay DA, Phillips WL, Jones G V. 1997. The North Atlantic subtropical anticyclone. Journal of Climate 10:728-744.

DOI: $10.1175 / 1520-0442(1997) 010<0728$ :TNA$\mathrm{SA}>2.0 . \mathrm{CO} ; 2$

DiMego GJ, Bosart LF, Endersen GW. 1976. An examination of the frequency and mean conditions surrounding frontal incursions into the Gulf of Mexico and Caribbean Sea. Monthly Weather Review 104:709-718. DOI: 10.1175/1520-0493(1976)104<0709:AEOT$\mathrm{FA}>2.0 . \mathrm{CO} ; 2$

Estoque MA. 1962. The sea breeze as a function of the prevailing synoptic situation. Journal of the Atmospheric Sciences 19(3):244-250.

DOI: $10.1175 / 1520-0469(1962) 019<0244$ :TS$\mathrm{BAAF}>2.0 . \mathrm{CO} ; 2$

Fiedler F, Panofsky HA. 1970. Atmospheric scales and spectral gaps. Bulletin of the American Meteorological Society 51:1114-1120.

DOI: $10.1175 / 1520-0477(1970) 051<1114$ :ASASG $>2.0 . \mathrm{CO} ; 2$

Figueroa-Espinoza B, Salles P, Zavala-Hidalgo J. 2014. On the wind power potential in the northwest of the Yucatán Peninsula in Mexico. Atmósfera 27(1):77-89. DOI: 10.1016/S0187-6236(14)71102-6. 
Gille ST, Llewellyn-Smith SG, Lee SM. 2003. Measuring the sea breeze from QuikSCAT scatterometry. Geophysical Research Letters 30(3):14-1:14-4.

DOI: 10.1029/2002GL016230

Henry WK. 1979. Some aspects of the fate of cold fronts in the Gulf of Mexico. Monthly Weather Review 107:1078-1082.

DOI: $10.1175 / 1520-0493(1979) 107<1078:$ SAOT$\mathrm{FO}>2.0 . \mathrm{CO} ; 2$

Hirsch ME, DeGaetano AT, Colucci SJ. 2001. An East Coast winter storm climatology. Journal of Climate 14:882899. DOI: 10.1175/1520-0442(2001)014<0882:AE$\mathrm{CWSC}>2.0 . \mathrm{CO} ; 2$

INEGI. 2001. Conjunto de datos vectoriales de la Carta batimétrica internacional del Mar Caribe y Golfo de México (IBCCA) Hoja 1-06: escala 1:1,000,000. Instituto Nacional de Geografía y Estadística, Mexico. Available at http://www.beta.inegi.org.mx/app/mapa $\mathrm{s} / ? \mathrm{t}=0150003000000000$ andtg $=3614$ (accessed July 20, 2018).

INEGI. 2013. Datos de relieve. Continuo de Elevaciones Mexicano 3.0 (CEM 3.0). Instituto Nacional de Geografía y Estadística, Mexico. Available at http:// www.inegi.org.mx/geo/contenidos/datosrelieve/continental/descarga.aspx (accessed July 20, 2018).

Janjic Z, Black T, Pyle M, Rogers E, Chuang HY, DiMego G. 2005. High-resolution applications of the WRF NMM. In Preprints, 21st Conference on Weather Analysis and Forecasting/17th Conference on Numerical Weather Prediction. American Meteorological Society, Washington, DC. Available at: https:// ams.confex.com/ams/WAFNWP34BC/techprogram/ paper_93724.htm

Kimball SK, Mulekar MS. 2004. A 15-year climatology of North Atlantic tropical cyclones. Part I: Size parameters. Journal of Climate 17:3555-3575.

DOI: $10.1175 / 1520-0442(2004) 017<3555$ :AYCONA $>2.0$. CO; 2

Lagerloef GSE, Bernstein RL. 1988. Empirical orthogonal function analysis of advanced very high-resolution radiometer surface temperature patterns in Santa Barbara Channel. Journal of Geophysical Research: Oceans 93:6863-6873. DOI: 10.1029/JC093iC06p06863

Lalas DP, Asimakopoulos DN, Deligiorgi DG, Helmis CG. 1983. Sea-breeze circulation and photochemical pollution in Athens, Greece. Atmospheric Environment (1967) 17:1621-1632.

DOI: $10.1016 / 0004-6981(83) 90171-3$
Legler DM. 1983. Empirical orthogonal function analysis of wind vectors over the tropical Pacific region. Bulletin of the American Meteorological Society 64:234-241.

DOI: $10.1175 / 1520-0477(1983) 064<0234$ :EOF$\mathrm{AOW}>2.0 . \mathrm{CO} ; 2$

Lutgens FK, Tarbuck EJ. 2013. The atmosphere: An introduction to meteorology. Pearson Education, New Jersey, $528 \mathrm{pp}$.

Ludwig FL, HorelJ, Whiteman CD. 2004. UsingEOF analysis to identify important surface wind patterns in mountain valleys. Journal of Applied Meteorology 43:969-983. DOI: 10.1175/1520-0450(2004)043<0969:UEATII $>2.0 . \mathrm{CO} ; 2$

Masselink G. 1998. The effect of sea breeze on beach morphology, surf zone hydrodynamics and sediment resuspension. Marine Geology 146:115-135.

DOI: 10.1016/S0025-3227(97)00121-7

Melo-González NM, Muller-Karger FE, Estrada SC, De los Reyes RP, del Río IV, Pérez PC, Arenal IM. 2000. Near-surface phytoplankton distribution in the western Intra-Americas Sea: The influence of El Niño and weather events. Journal of Geophysical Research: Oceans 105:14029-14043.

Miller STK, Keim BD, Talbot RW, Mao H. 2003. Sea breeze: Structure, forecasting, and impacts. Reviews of Geophysics 41(3):1-1:1-31.

DOI: 10.1029/2003RG000124

North GR, Bell TL, Cahalan RF, Moeng FJ. 1982. Sampling errors in the estimation of empirical orthogonal functions. Monthly Weather Review 110:699-706. DOI: 10.1175/1520-0493(1982)110<0699:SEITE$\mathrm{O}>2.0 . \mathrm{CO} ; 2$

Paden CA, Abbott MR, Winant CD. 1991. Tidal and atmospheric forcing of the upper ocean in the Gulf of California: 1. Sea surface temperature variability. Journal of Geophysical Research: Oceans 96:18337-18359. DOI: 10.1029/91JC01597

Pandžić K, Likso T. 2005. Eastern Adriatic typical wind field patterns and large-scale atmospheric conditions. International journal of Climatology 25:81-98. DOI: $10.1002 /$ joc. 1085

Pasch RJ. 2015. 2014 Atlantic hurricane season. National Hurricane Center Annual Summary. Available at https:// www.nhc.noaa.gov/data/tcr/summary_atlc_2014.pdf (accessed June 2, 2018).

Pérez RA, Ortiz RJC, Bejarano ALF, Otero DL, Restrepo LJC, Franco HA. 2018. Sea breeze in the Colombian 
Caribbean coast. Atmósfera 31:389-406.

DOI: 10.20937/ATM.2018.31.04.06

Pérez-Santos I, Schneider W, Sobarzo M, Montoya-Sán-

chez R, Valle-Levinson A, Garcés-Vargas J. 2010. Surface wind variability and its implications for the Yucatán basin-Caribbean Sea dynamics. Journal of Geophysical Research: Oceans 115(C10).

DOI: 10.1029/2010JC006292

Piolee JF, Bentamy A. 2002. QuikSCAT scatterometer mean wind field products user manual. L'Institut Français de Recherche pour l'Exploitation de la Mer/ Centre ERS d'Archivage et de Traitement. Available at: http://apdrc.soest.hawaii.edu/doc/qscat_mwf.pdf (accessed December 10, 2018).

Reyes-Mendoza RO, Mariño-Tapia I, Herrera-Silveira J, Ruiz-Martínez G, Enriquez C, Largier JL. 2016. The effects of wind on upwelling off Cabo Catoche. Journal of Coastal Research 32:638-650.

DOI: 10.2112/JCOASTRES-D-15-00043.1

Rolph G, Stein A, Stunder B. 2017. Real-time environmental applications and display system: READY. Environmental Modelling and Software 95:210-228. DOI: $10.1016 /$ j.envsoft.2017.06.025

Romero-Centeno R, Zavala-Hidalgo J, Gallegos A, O'Brien JJ. 2003. Isthmus of Tehuantepec wind climatology and ENSO signal. Journal of Climate 16:26282639. DOI: 10.1175/1520-0442(2003)016<2628:IOTWCA $>2.0 . \mathrm{CO} ; 2$

Salas de León DA, Monreal Gómez MA, Ramírez JA. 1992. Periodos característicos en las oscilaciones de parámetros meteorológicos en Cayo Arcas, México. Atmósfera 5:193-205.

Schultz DM. 2005. A review of cold fronts with prefrontal troughs and wind shifts. Monthly Weather Review 133:2449-2472. DOI: 10.1175/MWR2987.1

Serra YL, Kiladis GN, Hodges KI. 2010. Tracking and mean structure of easterly waves over the Intra-Americas Sea. Journal of Climate 23:4823-4840.

DOI: $10.1175 / 2010 J C L I 3223.1$

Simpson JE. 1994. Sea breeze and local winds. Cambridge University Press, New York, 252 pp.

Soler-Bientz R, Watson S, Infield D. 2010. Wind characteristics on the Yucatán Peninsula based on short term data from meteorological stations. Energy Conversion and Management 51:754-764.

DOI: $10.1016 /$ j.enconman.2009.10.032
Stein AF, Draxler RR, Rolph GD, Stunder BJB, Cohen MD, Ngan F. 2015. NOAA's HYSPLIT atmospheric transport and dispersion modeling system. Bulletin of the American Meteorological Society 96:2059-2077. DOI: 10.1175/BAMS-D-14-00110.1

Taylor-Espinosa N. 2009. Análisis y visualización de la componente diurna de los vientos en el sur del Golfo de México. B.Sc. thesis. Universidad Nacional Autónoma de México.

Thomson RE, Emery WJ. 2014. Data analysis methods in physical oceanography. 3rd ed. Elsevier, 728 pp.

DOI: $10.1016 / \mathrm{C} 2010-0-66362-0$

Torres-Freyermuth A, Puleo JA, DiCosmo N, Allende-Arandía ME, Chardón-Maldonado P, López J, Figueroa-Espinoza B, de Alegria-Arzaburu AR, Figlus J, Briggs TMR, de la Roza J, Candela J. 2017. Nearshore circulation on a sea breeze dominated beach during intense wind events. Continental Shelf Research 151:40-52. DOI: 10.1016/j.csr.2017.10.008

Turrent C, Zaitsev O. 2014. Seasonal cycle of the near-surface diurnal wind field over the bay of La Paz, Mexico. Boundary-layer meteorology 151:353-371.

DOI: $10.1007 / \mathrm{s} 10546-014-9908-4$

Vecchi GA, Zhao M, Wang H, Villarini G, Rosati A, Kumar A, Held IM, Gudgel R. 2011. Statistical-dynamical predictions of seasonal North Atlantic hurricane activity. Monthly Weather Review 139:1070-1082.

DOI: 10.1175/2010MWR3499.1

Von Storch H, Zwiers FW. 1999. Statistical analysis in climate research. Cambridge University Press, 496 pp. DOI: $10.1017 / \mathrm{CBO} 9780511612336$

Xian Z, Pielke RA. 1991. The effects of width of landmasses on the development of sea breezes. Journal of Applied Meteorology 30(9):1280-1304.

DOI: $10.1175 / 1520-0450(1991) 030<1280$ :TEOWOL $>2.0 . \mathrm{CO} ; 2$

Zavala-Hidalgo J, Romero-Centeno R, Mateos-Jasso A, Morey SL, Martínez-López B. 2014. The response of the Gulf of Mexico to wind and heat flux forcing: What has been learned in recent years? Atmósfera 27:317334. DOI: 10.1016/S0187-6236(14)71119-1 